\title{
Thermal Performance Analyses of Multiborehole Ground Heat Exchangers
}

\author{
Wanjing Luo, ${ }^{1}$ Changfu Tang, ${ }^{2}$ Yin Feng, ${ }^{3}$ and Pu Miao ${ }^{4}$ \\ ${ }^{1}$ School of Energy Resources, China University of Geosciences (Beijing), Beijing 100083, China \\ ${ }^{2}$ Exploration Research Institute, Anhui Provincial Bureau of Coal Geology, Hefei, Anhui 230088, China \\ ${ }^{3}$ University of Louisiana at Lafayette, Lafayette, LA 70504, USA \\ ${ }^{4}$ Beijing Key Laboratory of Unconventional Natural Gas Geological Evaluation and Development Engineering, Beijing 100083, China
}

Correspondence should be addressed to Wanjing Luo; luowanjing@cugb.edu.cn

Received 30 June 2017; Revised 24 September 2017; Accepted 14 November 2017; Published 11 December 2017

Academic Editor: Paolo Fulignati

Copyright (c) 2017 Wanjing Luo et al. This is an open access article distributed under the Creative Commons Attribution License, which permits unrestricted use, distribution, and reproduction in any medium, provided the original work is properly cited.

\begin{abstract}
Geothermal energy known as a clean, renewable energy resource is widely available and reliable. Ground heat exchangers (GHEs) can assist the development of geothermal energy by reducing the capital cost and greenhouse gas emission. In this paper, a novel semianalytical method was developed to study the thermal performance of multiborehole ground heat exchangers (GHEs) with arbitrary configurations. By assuming a uniform inlet fluid temperature (UIFT), instead of uniform heat flux (UHF), the effects of thermal interference and the thermal performance difference between different boreholes can be examined. Simulation results indicate that the monthly average outlet fluid temperatures of GHEs will increase gradually while the annual cooling load of the GHEs is greater than the annual heating load. Besides, two mechanisms, the thermal dissipation and the heat storage effect, will determine the heat transfer underground, which can be further divided into four stages. Moreover, some boreholes will be malfunctioned; that is, boreholes can absorb heat from ground when the GHEs are under the cooling mode. However, as indicated by further investigations, this malfunction can be avoided by increasing borehole spacing.
\end{abstract}

\section{Introduction}

Geothermal energy is attractive due to its enormous potential, renewability, availability, and low gas emission. With improvements in drilling, completion, and energy conversion systems, geothermal energy is becoming an economically viable alternative. Nonetheless, many challenges remain. The development of geothermal resource may be impeded by high capital requirements. Produced groundwater needs to be reinjected rather than disposing to surface waters to avoid environmental impacts, which raises the operational difficulties and maintaining cost. The ground heat exchangers (GHEs) such as geothermal heat pumps can reduce the cost effectively, and the close-loop system will eliminate the necessary of any reinjections (no groundwater produced). The ground can offer a steady and large heat storage medium as a heat source/sink and for thermal energy utilization, such as geothermal heat pumps. As one of the main geothermal heat pump technologies, the ground source heat pump
(GSHP) has been widely used as a viable and economical alternative to traditional air conditioning systems owing to its high-efficient performance in the world [1-7]. It is well known that the efficiency of GSHP is related to the outlet fluid temperature of ground heat exchangers (GHEs), which is required to be in a certain range. Hence, it is very important to develop a reliable and efficient method to model the thermal performance of GHEs in order to predict/optimize the outlet fluid temperature [2-7].

Many methods, such as analytical/semianalytical, numerical method, and fractal methods [8-27], have been reported in literatures for heat transfer analysis. To study the underground heat transfer for GHEs, the semianalytical and numerical method are always preferred [8-22]. Generally, the model for underground heat transfer consists of two submodels [6-8], which account for the heat transfer inside the boreholes and outside the boreholes, respectively [2-7].

For the heat transfer inside the borehole, a steady-state process is usually approximated using $1 \mathrm{D}, 2 \mathrm{D}$, or quasi-3D 
models [7]. Regarding the heat transfer outside the borehole, several models are available [9-12], such as line source model, cylinder source model, and finite length source model. Nevertheless, these models mentioned above are normally only valid for single borehole with a constant heat flux. In a real field, a single borehole is usually not sufficient to satisfy load demands, as the GHEs always consist of multiple boreholes. For a multiple-borehole system, the heat transfer capacity for each borehole may be reduced due to the thermal interference among different boreholes. Thus, simulating heat transfer for a multiborehole GHEs is a very important task. For this purpose, semianalytical methods [8-14] and numerical methods [14-19] are the main approaches. Hellström [15] presented a numerical method for simulating ground heat storage systems consisting of densely packed ground loop heat exchangers used for seasonal thermal energy storage. In Hellström's model, a duct ground heat storage system (DST) is defined to divide the ground storage volume with multiple boreholes into two regions: one "global" region, where the ground temperature is solved with a two-dimensional finite difference scheme and one "local" region, the temperature of which is calculated by one-dimensional numerical method. Zhang [19] used a finite element method to investigate the thermal performance of each borehole in a multiple-borehole system with a thermal effectiveness factor. It demonstrated that the thermal effectiveness factor for each borehole is less than 1 due to the thermal interference.

Although the numerical simulations are flexible, they require significantly more computational time, which is not efficient for practical applications. In contrast, the semianalytical methods are more convenient and have been widely used in practice $[13,14,23]$. With the help of nondimensional temperature response " $g$-functions" that can be calculated from numerical methods, Eskilson [14] used the superposition principle to study the thermal response of GHEs. However, Eskilson's " $g$-function" method is not practically convenient as the " $g$-functions" is not universal and needs to be precomputed with respect to the GHEs' configurations with numerical approaches. Many semianalytical methods have also been presented with the superposition principle with respect to different forms of " $g$-function" $[12,13]$.

However, an unreasonable assumption with uniform heat flux (UHF) was adopted for these semianalytical methods mentioned above [12-14]. As a result, only the overall performance of GHEs, such as the average outlet fluid temperature and total heat flux of the GHEs, can be studied, while the heat capacity difference between different boreholes cannot be well examined. Furthermore, it has been reported that the UHF assumptions may give rise to errors when predicting the thermal performance of multiborehole GHEs. Claesson and Javed [23] noticed errors between their analytical $g$-functions and Eskilson's $g$-functions for different configurations, and the errors become greater with more boreholes and increase with time. Similar results were also pointed out by Malayappan and Spitler [24] using a numerical approach. They found that the GHEs system could be oversized by around 5-6\% with uniform heat flux assumptions used in a semianalytical approach. The reason why the UHF assumptions are inaccurate is that the nonuniform heat fluxes are common

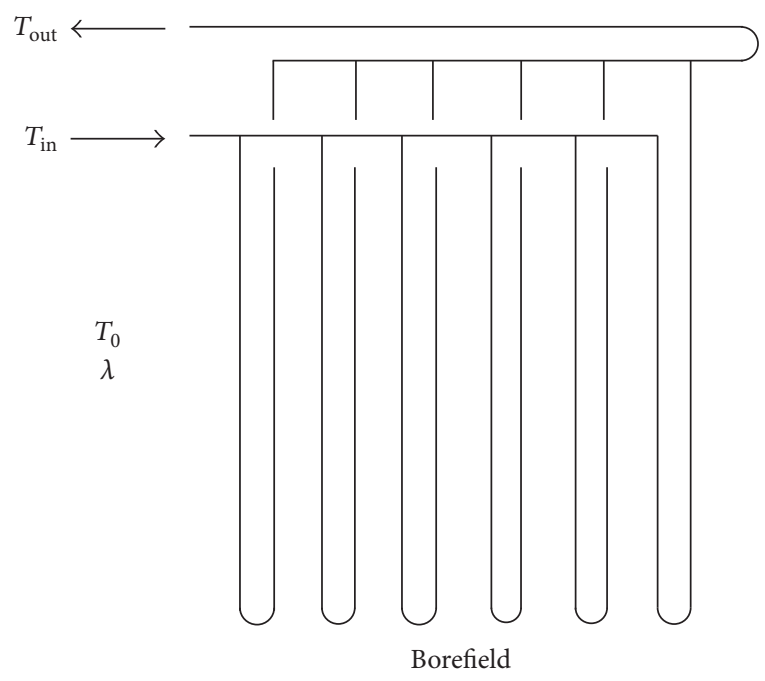

FIgURE 1: Schematic for multiborehole GHEs.

for the heat transfer of multiple boreholes. For example, for a bundle of boreholes, the outer boreholes have higher heat fluxes than the inner boreholes. However, the heat flux difference between boreholes due to the interference cannot be considered using the UHF assumptions. Furthermore, by noticing that the fluids entering different boreholes actually come from the same container (Figure 1), and the effluent fluid from each borehole will be accumulated by a collector before entering the heat pump, the assumption of uniform inlet fluid temperatures (UIFT) for all boreholes in GHEs is more reasonable.

Based on these findings, the main objective of this paper is to develop a semianalytical solution to simulate the underground heat transfer of multiborehole GHEs with the UIFT assumption. The new method can be used for simulating the performance of the GHEs with arbitrary configurations. Furthermore, the effects of the heat capacity of each borehole and the thermal interference between different boreholes on the thermal performance of GHEs are also examined. Overall, this paper is organized as follows: in Section 2, the basic heat transfer model with UIFT is presented and solved semianalytically; in Section 3, the thermal performance of GHEs is studied with this new method. Finally, discussions and conclusions are presented in Section 4.

\section{Heat Transfer Model under Ground for Multiborehole GHEs}

In this section, the basic thermal response equation for single borehole will be presented followed by the development of heat transfer model for multiple boreholes as well as the corresponding semianalytical solution.

\subsection{Thermal Response for Single Borehole. The following} assumptions are made.

(1) The ground is regarded as an infinite homogeneous medium with thermal conductivity, $\lambda$, volume specific heat, $(\rho c)$, and constant initial temperature, $T_{0}$. 
(2) The borehole is of depth $H$ with a radius $r_{b}$. The heat transfer inside the borehole is assumed to be at steady state, and the total thermal resistance in borehole is $R_{b}$.

(3) The specific heat of fluid is denoted as $c_{f}$, and the mass flow rate is denoted as $\dot{m}_{f}$.

(4) The thermal load of the single borehole can be denoted by a series of step heat fluxes, $\left(t_{m}, q_{m}\right), m=1,2, \ldots, M_{0}$, where $M_{0}$ is the total number of steps.

With the above assumptions, the thermal response at time $t\left(t_{M-1}<t<t_{M}\right)$ for single borehole can be written as follows [7]:

$$
\begin{aligned}
\Delta T_{f}(t) & =T_{f}(t)-T_{0} \\
& =q(t) \cdot R_{b}+\sum_{m=1}^{M}\left(q_{m}-q_{m-1}\right) \cdot T_{u}\left(r_{b}, t-t_{m-1}\right) \\
& =q(t) \cdot R_{b}+\sum_{m=1}^{M} \Delta q_{m} \cdot T_{u}\left(r_{b}, t-t_{m-1}\right),
\end{aligned}
$$

where $T_{f}$ denotes the average fluid temperature, $q$ is the heat flux, and $T_{u}$ is the thermal response under unity heat flux, which can be written in the form of infinite line source model, cylinder source model, finite length line source model, or $g$ functions. If the infinite line source model is used, $T_{u}$ satisfies the following [7]:

$$
T_{u}(r, t)=\left(\frac{1}{4 \pi \lambda}\right) \cdot \operatorname{Ei}\left(\frac{r^{2}}{2 \alpha t}\right),
$$

with exponential integral function Ei:

$$
-\operatorname{Ei}(-x)=\int_{x}^{\infty}\left(\frac{e^{-u}}{u}\right) d u
$$

where $\alpha$ in (2) denotes thermal diffusive coefficient and $\alpha=$ $\lambda / \rho c$. In addition, the average fluid temperature $T_{f}$ yields

$$
T_{f}=\frac{\left(T_{\text {in }}+T_{\text {out }}\right)}{2},
$$

where $T_{\text {in }}$ and $T_{\text {out }}$ indicate the inlet fluid temperature and outlet fluid temperature, respectively. The heat flux $q$ of the borehole can be given by the following:

$$
q=\left(\frac{\beta}{2}\right) \cdot\left(T_{\text {in }}-T_{\text {out }}\right)
$$

with coefficient $\beta$

$$
\beta=\frac{2 \dot{m}_{f} c_{f}}{H} .
$$

Combining (4) and (5) leads to

$$
\begin{gathered}
T_{f}=T_{\text {in }}-\frac{q}{\beta}, \\
T_{\text {out }}=T_{\text {in }}-\frac{2 q}{\beta} .
\end{gathered}
$$

Substituting (7) to (1) yields

$$
\begin{array}{r}
\Delta T_{\mathrm{in}}(t)=q(t) \cdot R_{b t}+\sum_{m=1}^{M} \Delta q_{m} \cdot T_{u}\left(r_{b}, t-t_{m-1}\right), \\
t_{M-1}<t<t_{M}
\end{array}
$$

with

$$
R_{b t}=R_{b}+\frac{1}{\beta}
$$

2.2. Thermal Response for GHEs with Multiple Boreholes with UIFT Assumptions. It is assumed that the GHEs consist of $N$ boreholes with the same borehole radius $r_{b}$ and the same inlet temperature $T_{\text {in }}$. The $i$ th borehole is located at $\left(x_{w i}, y_{w i}\right)$ with borehole thermal resistance $R_{b i}$, outlet temperature $T_{\text {out }, i}$, average fluid temperature $T_{f, i}$, and mass flow rate $\dot{m}_{f i}$. The heat load of the GHEs can also be denoted by a series of step heat fluxes, $\left(t_{m}, Q_{m}\right), m=1,2, \ldots, M_{0}$. The heat flux for the $i$ th borehole is $\left(t_{m}, q_{i, m}\right), m=1,2, \ldots, M_{0}$.

The inlet temperature $T_{\text {in }}$ and outlet temperature $T_{\text {out }}$ of GHEs can be calculated in the following form, respectively:

$$
\begin{aligned}
T_{\mathrm{in}} & =\frac{\sum_{i=1}^{N}\left(\dot{m}_{f i} T_{\mathrm{in}, i}\right)}{\sum_{i=1}^{N} \dot{m}_{f i}}, \\
T_{\text {out }} & =\frac{\sum_{i=1}^{N}\left(\dot{m}_{f i} T_{\text {out }, i}\right)}{\sum_{i=1}^{N} \dot{m}_{f i}} .
\end{aligned}
$$

By applying the superposition principle to (9), the inlet fluid temperature at time $t\left(t_{M-1}<t<t_{M}\right)$ for the $i$ th borehole is given as follows:

$$
\begin{aligned}
\Delta T_{\text {in }}(t)= & q_{i}(t) \cdot R_{b t i}+\sum_{j=1}^{N} \sum_{m=1}^{M} \Delta q_{j, m} \\
& \cdot \Delta T_{u i j}\left(r_{i j}, t-t_{m-1}\right),
\end{aligned}
$$

where $r_{i j}$ is the distance between $i$ th borehole and the $j$ th borehole:

$$
r_{i j}=\sqrt{\left(x_{w j}-x_{w i}\right)^{2}+\left(y_{w j}-y_{w i}\right)^{2}} .
$$

At time $t_{M}\left(M=1,2, \ldots, M_{0}\right)$, inlet temperature for the $i$ th borehole has the following form:

$$
\begin{gathered}
\sum_{j=1}^{N} \Delta q_{j, M} \cdot \Delta T_{u i j}\left(r_{i j}, t_{M}-t_{M-1}\right)+\Delta q_{i, M} \cdot R_{b t i}-\Delta T_{\text {in }} \\
=\sum_{j=1}^{N} \sum_{m=1}^{M-1} \Delta q_{j, m} \cdot \Delta T_{u i j}\left(r_{i j}, t_{M}-t_{m-1}\right)+\sum_{m=1}^{M-1} \Delta q_{i, m} \\
\cdot R_{b t i}, \quad i=1,2, \ldots, N .
\end{gathered}
$$


There are $N+1$ unknowns in (15) at time $t_{M}$, which are $\Delta q_{1, M}, \Delta q_{2, M}, \ldots, \Delta q_{N, M}, \Delta T_{\mathrm{in}}$. In addition, the heat fluxes for each borehole satisfy

$$
\sum_{i=1}^{N} \Delta q_{i, M}=\Delta Q_{M}
$$

It is worth mentioning that (15) and (16) should be fully coupled to obtain the semianalytical solution for multiborehole GHEs. In contrast, the method with UHF assumptions, where the heat flux for each borehole is identical, and the temperature response can be calculated in a much simpler way [14].

Furthermore, (15) and (16) can be written in the following matrix form:

$$
A^{M} \vec{q}^{M}=\vec{b}^{M}
$$

with

$$
\begin{aligned}
\vec{A}^{M} & =\left(\begin{array}{cccc}
\left(\Delta T_{u 11, M}+R_{b t 1}\right) & \cdots & \Delta T_{u 1 N, M} & -1 \\
\vdots & \ddots & \Delta T_{u 2 N, M} & \vdots \\
\Delta T_{u N 1, M} & \cdots & \left.\Delta T_{u N N, M}+R_{b t N}\right) & -1 \\
1 & \cdots & 1 & 0
\end{array}\right), \\
\Delta \vec{q}^{M} & =\left(\begin{array}{c}
\Delta q_{1, M} \\
\vdots \\
\Delta q_{N, M} \\
\Delta T_{\mathrm{in}, M}
\end{array}\right), \\
\vec{b}^{M} & =\left(\begin{array}{c}
\sum_{j=1}^{N} \sum_{m=1}^{M-1} \Delta q_{j, m} \cdot \Delta T_{u 1 j}\left(r_{1 j}, t_{M}-t_{m-1}\right)+\sum_{m=1}^{M-1} \Delta q_{1, m} \cdot R_{b t} \\
\vdots \\
\sum_{j=1}^{N} \sum_{m=1}^{M-1} \Delta q_{j, m} \cdot \Delta T_{u N j}\left(r_{N j}, t_{M}-t_{m-1}\right)+\sum_{m=1}^{M-1} \Delta q_{N, m} \cdot R_{b t} \\
\Delta Q_{M}
\end{array}\right) .
\end{aligned}
$$

Then, (17) can be solved by Gauss elimination to obtain $\Delta T_{\mathrm{in}, M}$ and $\Delta q_{i, M}$ at time $t_{M}\left(M=1,2, \ldots, M_{0}\right)$ from time $t_{1}$ to $t_{M 0}$ step by step. In subsequence, the outlet temperatures of GHEs and boreholes can be also calculated.

In particular, at time $t_{1}(M=1)$, vector $\Delta \mathbf{q}, \mathbf{b}$, and matrix A can be given as follows:

$$
\begin{gathered}
\overrightarrow{\Delta \vec{q}}^{M}=\left(\begin{array}{c}
q_{1,1} \\
\vdots \\
q_{N, 1} \\
\Delta T_{\mathrm{in}, 1}
\end{array}\right), \\
\overrightarrow{\mathbf{b}}^{M}=\left(\begin{array}{c}
0 \\
\vdots \\
0 \\
\Delta Q_{1}
\end{array}\right),
\end{gathered}
$$

$$
\begin{aligned}
& \overrightarrow{\mathbf{A}}^{M} \\
& =\left(\begin{array}{cccc}
\left(\Delta T_{u 11,1}+R_{b t 1}\right) & \cdots & \Delta T_{u 1 N, 1} & -1 \\
\vdots & \ddots & \Delta T_{u 2 N, 1} & \vdots \\
\Delta T_{u N 1,1} & \cdots & \left(\Delta T_{u N N, 1}+R_{b t N}\right) & -1 \\
1 & \cdots & 1 & 0
\end{array}\right) .
\end{aligned}
$$

\section{Results}

In this section, we first validate the new semianalytical method by comparing with the results from a numerical method [19] and experimental data [25, 26]. Then the new semianalytical method is used for heat transfer analysis of multiborehole GHEs with different configurations under varying heat fluxes. To conduct simulations, following data are required: the ground parameters including undisturbed ground temperature, ground thermal conductivity, and 
TABLE 1: Simulation input data [19].

\begin{tabular}{lc}
\hline Borehole spacing & $4.572 \mathrm{~m}$ \\
Borehole diameter & $0.1524 \mathrm{~m}$ \\
Ground soil density & $2691.36 \mathrm{~kg} / \mathrm{m}^{3}$ \\
Borehole wall temperature & $37.78^{\circ} \mathrm{C}$ \\
Undisturbed ground temperature & $22.22^{\circ} \mathrm{C}$ \\
Ground thermal conductivity & $2.422 \mathrm{~W} /(\mathrm{m} \cdot \mathrm{K})$ \\
\hline
\end{tabular}

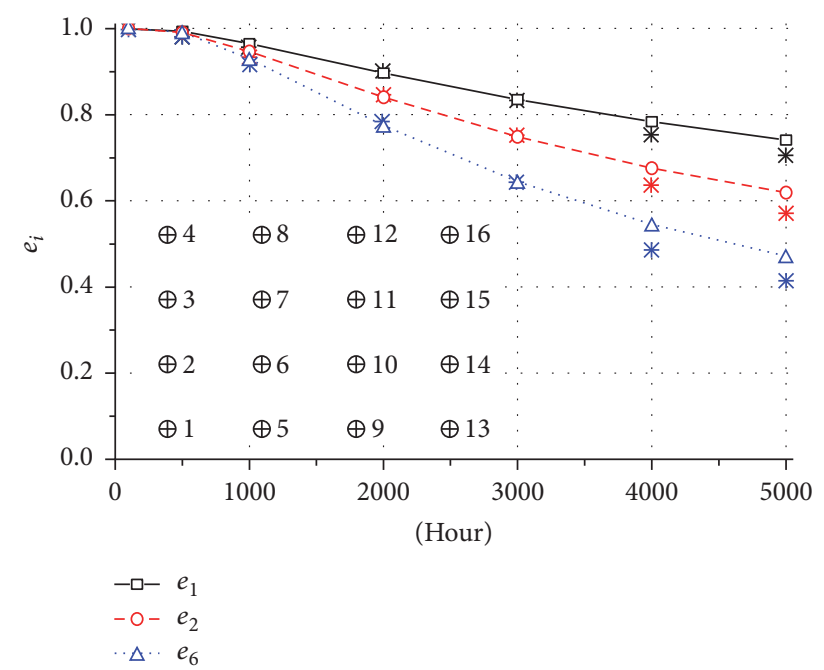

FIgURE 2: Comparison results of thermal effectiveness for a $4 \times 4$ borehole field [19].

ground volume specific heat; borehole parameters including borehole configuration, borehole spacing, borehole depth, borehole spacing, borehole diameter, U-tube inner diameter, U-tube outer diameter, and borehole thermal resistance; circulating fluid parameters including fluid density, specific heat capacity and fluid flow rate, and heat load of GHEs.

\subsection{Model Validation}

Case 1. In [19], Zhang examined the thermal performance of GHEs with square $4 \times 4$ borehole field by a numerical method. Constant temperature constraints were specified for the borehole wall and the far-field boundary. The simulation input data are listed at Table 1.

In order to examine the effects of multiple boreholes, Zhang [19] introduced a thermal effectiveness, which is defined as the ratio of heat flux for a specific borehole in a multiple-borehole filed to heat flux produced by a single isolated borehole:

$$
e_{i}=\frac{q_{i, N}}{q_{s 1}},
$$

where $q_{i, N}$ is the heat flux for the $i$ th borehole in $N$-borehole filed and $q_{s 1}$ is the heat flux produced by single isolated borehole.

Figure 2 presents the comparison results of thermal effectiveness of the 1st borehole, 2nd borehole, and 6th borehole for a square $4 \times 4$ borehole field (Figure 5.2 in [19]).
TABLE 2: Experimental data [26].

\begin{tabular}{lc}
\hline Borehole depth & $75 \mathrm{~m}$ \\
Borehole spacing & $9 \mathrm{~m}$ \\
Borehole diameter & $114 \mathrm{~mm}$ \\
U-tube inner diameter & $21.8 \mathrm{~mm}$ \\
U-tube outer diameter & $26.7 \mathrm{~mm}$ \\
Undisturbed ground temperature & $17.3^{\circ} \mathrm{C}$ \\
Ground thermal conductivity & $2.3 \mathrm{~W} / \mathrm{m}-\mathrm{K}$ \\
Ground volume specific heat & $2012 \mathrm{~kJ} / \mathrm{m}^{3}-\mathrm{K}$ \\
Borehole thermal resistance & $0.1622 \mathrm{~m}-\mathrm{K} / \mathrm{W}$ \\
Fluid flow rate & $0.631 \mathrm{~kg} / \mathrm{s}$ \\
\hline
\end{tabular}

Thermal effectiveness for different boreholes calculated by the new method shows a good agreement with Zhang (star in Figure 2) before 3000 hours. The discrepancies between the two methods after 3000 hours are mainly attributed to the fact that constant temperature constraints were specified for the far-field boundary in [19], while the outer boundary in our simulations is assumed to be infinite.

Case 2. The second comparisons are based on an experimental system at Oklahoma State University [25]. The GHEs consist of three boreholes arranged in line. Experimental data are listed in Table 2 . The monthly average heat extraction and rejection rates [26] for the GHEs are presented in Figure 3(a). Heat extraction from ground is defined as negative while heat injection is defined as positive. It can be found in Figure 3(b) that the monthly average outlet fluid temperature from our simulation follows the general trend of the experiment reasonably closely.

3.2. Heat Transfer Analysis for GHEs with Different Configurations of 9 Boreholes under Varying Heat Fluxes. In this section, the new method will be used to study the thermal performance of 9-borehole GHEs with different configurations under varying heat fluxes. In particular, the effects of thermal interference and heat storage underground are discussed in detail. The monthly average heat fluxes used in simulation are displayed in Table 3. The total heating load is assumed to be more than the cooling load, with an annual average heat imbalance $32400 \mathrm{kWh}$. Parameters used in simulations are listed in Table 4. The simulation period lasts for 10 years (120 months).

3.2.1. Thermal Performance of $3 \times 3$ Square Array of Boreholes. We first investigate the thermal performance of $3 \times 3$ square array GHEs (Figure 4). Figure 5 shows the monthly average outlet fluid temperature for ten years. In each year, the monthly average outlet fluid temperatures vary with the thermal loads. Due to the annual heat imbalance, the outlet fluid temperature increases year over year gradually. For example, the average outlet fluid temperature in August in the 10th year increases about $3.5^{\circ} \mathrm{C}$ compared with that in the 1st year. Obviously, the temperature rise will improve the heating efficiency with respect to a higher entering fluid temperature of heat pump. However, the cooling efficiency of heat pump 


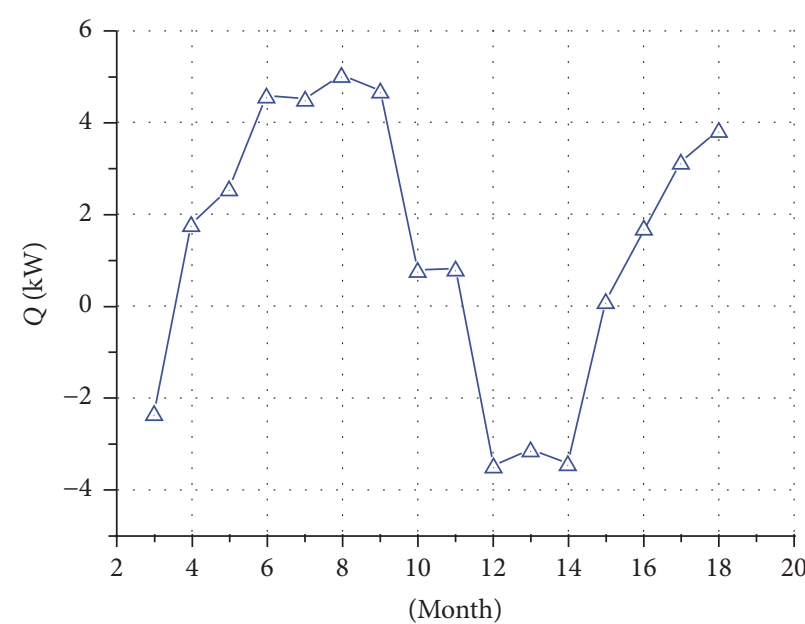

(a)

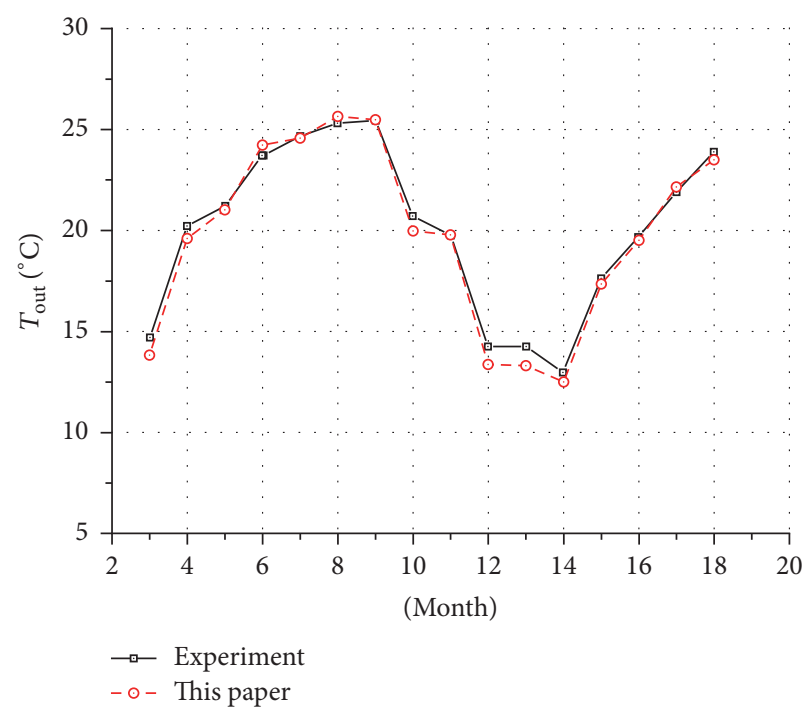

(b)

FIGURE 3: (a) Monthly average heat extraction/rejection rates; (b) comparison results of monthly average outlet fluid temperature [26].

TABLE 3: Monthly average heat extraction/rejection rates.

\begin{tabular}{lc}
\hline Month & Heat rate $(\mathrm{kW})$ \\
\hline Jan & -45 \\
Feb & -34.2 \\
Mar & -9 \\
Apr & 4.5 \\
May & 16.2 \\
Jun & 27 \\
Jul & 36.9 \\
Aug & 63.9 \\
Sep & 27.9 \\
Oct & 2.7 \\
Nov & -13.5 \\
Dec & -32.4 \\
\hline
\end{tabular}

TABLe 4: Simulation input data.

\begin{tabular}{lc}
\hline Borehole depth & $100 \mathrm{~m}$ \\
Borehole spacing & $5 \mathrm{~m}$ \\
Borehole diameter & $126 \mathrm{~mm}$ \\
Fluid mass flow rate & $2.651 \mathrm{~kg} / \mathrm{s}$ \\
Undisturbed ground temperature & $18^{\circ} \mathrm{C}$ \\
Ground thermal conductivity & $2 \mathrm{~W} / \mathrm{m}-\mathrm{K}$ \\
Ground heat capacity & $2000 \mathrm{~kJ} / \mathrm{m}^{3}-\mathrm{K}$ \\
Borehole thermal resistance & $0.12 \mathrm{~m}-\mathrm{K} / \mathrm{W}$ \\
\hline
\end{tabular}

will be reduced since the entering fluid temperature becomes higher. Severely, the heat pump could be malfunctioned while average outlet fluid temperature exceeds the specified highest entering fluid temperature of the heat pump.

There are two important aspects for the heat transfer of GHEs underground. One is that GHEs will reject heat into $\oplus 7$

$\oplus 8$

$\oplus 9$

$\bigoplus 4$

$\oplus 5$

$\oplus 6$

$\oplus 1$

$\oplus 2$

$\oplus 3$

FIGURE 4: Configuration of GHEs with $3 \times 3$ square borehole array.

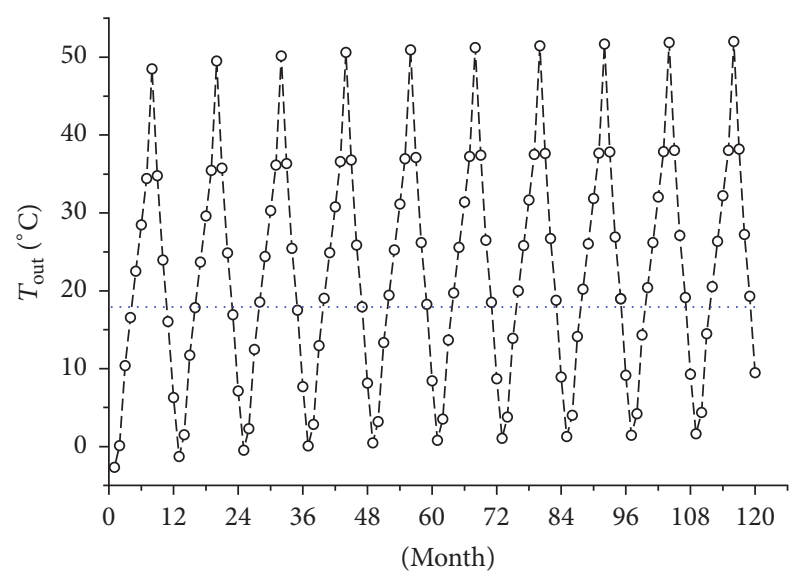

FIGURE 5: Monthly average outlet fluid temperature.

ground or extract heat from ground, whose efficiency is determined by the thermal dissipation underground. The other is the extracted or rejected heat can be stored underground, 


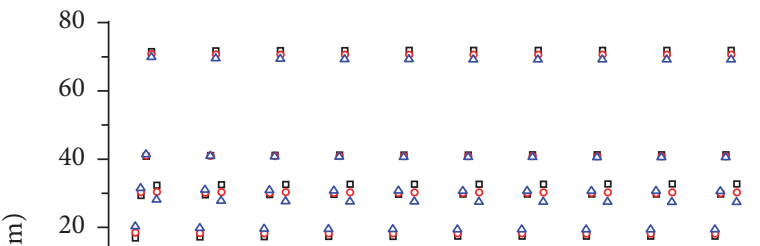

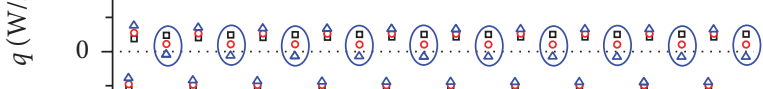

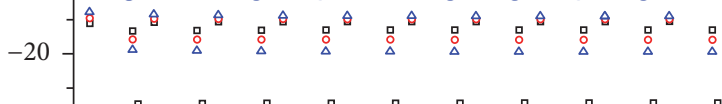

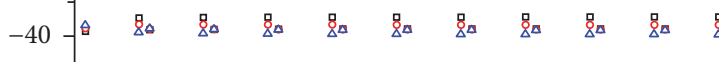

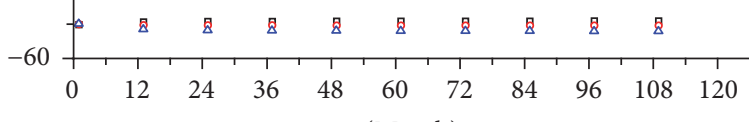

$$
\begin{aligned}
& \text { (Month) } \\
& \text { - } q_{1} \\
& \text { - } q_{2} \\
& \triangle q_{5}
\end{aligned}
$$

FIGURE 6: Monthly average heat fluxes for different boreholes $($ spacing $=5 \mathrm{~m})$.

which can be utilized by the GHEs later. Figure 6 shows the monthly average heat fluxes for individual boreholes, $q_{1}$ for the 1st borehole, $q_{2}$ for the 2nd borehole, and $q_{5}$ for the 5th borehole. In the first month, the thermal interference among boreholes is weak, and the difference of the heat fluxes $\left(q_{1}, q_{2}, q_{5}\right)$ is small. As time goes on, the borehole-to-borehole thermal interference becomes stronger. As a consequence, the borehole heat fluxes vary with respect to their different locations in the GHEs. According to the features of heat transfer, we can divide the heat flux process into four stages for a heat transfer period of one year,

(1) The 1st Stage (Feb-March). The GHEs extract heat from the ground and the thermal performance is mainly determined by the thermal dissipation. Thus, the thermal interference among boreholes could have a great influence on the heat flux. For example, the 1st borehole, which is located at the outer corner of the GHEs and least interfered, has the highest heat flux. In contrast, the 5th borehole, located in the middle of the GHEs and most interfered, has the smallest heat flux. Moreover, the ground will become a good heat sink for heat rejection of the GHEs due to the heat extraction in this stage.

(2) The 2nd Stage (April-July). The GHEs reject heat into the ground, and the thermal performance is mainly determined by the heat storage effect. Because the ground around the 5th borehole is less compensated due to the stronger thermal interference in the last stage, the 5th borehole has the best heat extraction condition, compared with other boreholes. As a result, the 5th borehole yields the highest heat flux in the GHEs.

(3) The 3rd Stage (August-October). The GHEs still reject heat into the ground; however, the effect of heat storage has dissolved, and the thermal performance is mainly determined by the thermal dissipation. Consistent with the situation in the 1st stage, the 5th borehole's heat flux is smaller than others due to the greater thermal interference. Furthermore, the heat rejected from the GHEs in the 2nd and 3rd stages will be stored in the ground, which makes the ground a good source for heating in the next stage, and the 5th borehole will enter a better heat extraction condition since the heat dissipation around the 5th borehole in last stage is hindered much more seriously due to the thermal interference.

(4) The 4th Stage (November-January). The GHEs extract heat from the ground, and the thermal performance is mainly determined by the heat storage effect. The ground plays an important role in supplying heat for the GHEs as a heat source, and the 5th borehole extracts more heat from ground than the other ones in the GHEs for the more heat accumulation around in last stage.

From the above discussion, we can conclude that while the thermal dissipation dominates, the heat flux of the borehole with stronger thermal interference is smaller. In contrast, while the heat storage effect plays a major role, the boreholes being strongly interfered will have a greater heat flux. This is because the hindrance of thermal dissipation around boreholes due to thermal interference provides a better condition while the ground acts as a heat source/sink for the GHEs working under the opposite mode.

Furthermore, we should note that, in October (circle in Figure 6) in the 3rd stage, the GHEs work under the cooling mode and reject heat into the ground; however, the 5th borehole absorbs heat from ground individually $\left(q_{5}<0\right)$, which implies that the 5th borehole is malfunctioned. This is because the heat accumulation around the 5th borehole is more severely due to the thermal interference, resulting in greater ground temperatures around. As a result, the 5th borehole can extract heat from the ground if the ground temperature around is high enough. Furthermore, we have also examined the effect of the borehole spacing on this phenomenon (Figures 7 and 8). It is shown that a larger spacing can weaken heat interference and the phenomenon will not be observed for a larger borehole spacing (Figure 8).

\subsubsection{Thermal Performance of Different Borehole Configura-} tions. In this section, we investigate thermal behaviors of 9borehole GHEs arranged in "<"-Shape with different angles, $\theta=\pi / 4, \pi / 2,3 \pi / 4, \pi$ (Figure 9).

Figure 10 presents the monthly average outlet fluid temperature with an angle of $\pi / 2$. It is shown that the highest temperature in August and the lowest temperature in January are lower than those in the $3 \times 3$ square array case. Table 5 presents the comparison results of lowest temperature and the highest temperature in the 10th year. We can find that, with an increasing angle, both of the average outlet fluid temperatures in August and January become higher, which will improve the heating efficiency of heat pump in January and decrease the cooling efficiency of heat pump in August.

Figure 11 presents the heat fluxes of the 1st-5th boreholes for $\theta=\pi / 4$. As suggested above, heat transfer process underground can also been divided into four stages. However, the 4th (or 6th), instead of the 5th borehole, is observed to 


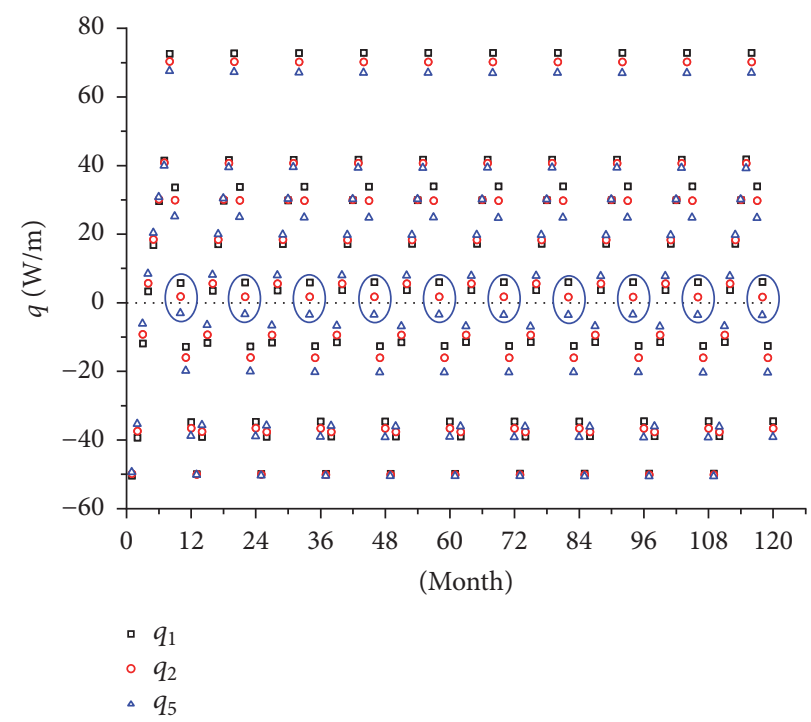

FIGURE 7: Monthly average heat fluxes for different boreholes (spacing $=4 \mathrm{~m}$ ).

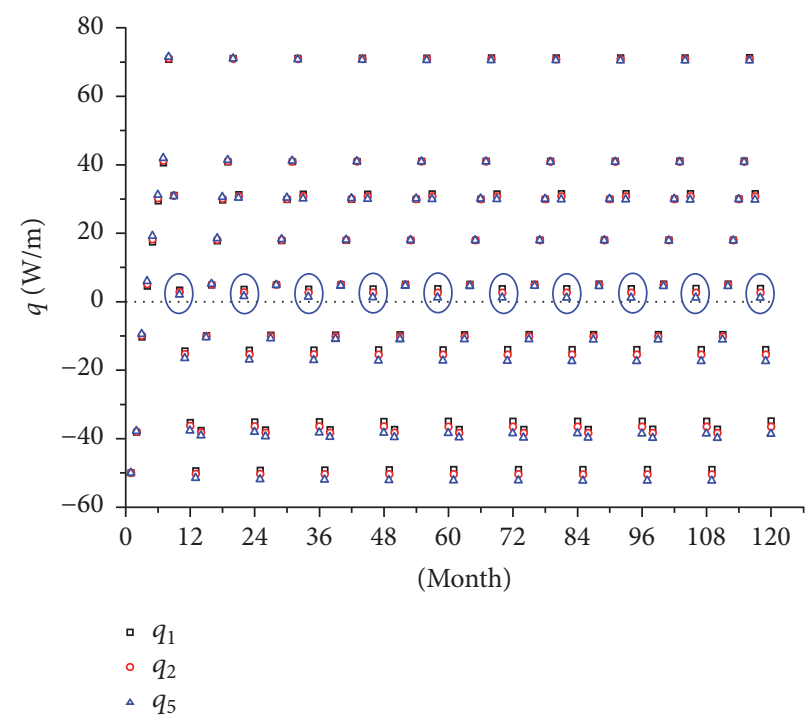

FIGURE 8: Monthly average heat fluxes for different boreholes (spacing = $7 \mathrm{~m}$ ).

be malfunctioned in October. Further investigation indicates that this phenomenon can also be eliminated by increasing the angle. For example, the heat flux of the 4 th borehole is positive in October with respect to an angle $\pi / 2$ (Figure 12).

\section{Conclusions}

In this paper, a novel semianalytical method to study the thermal performance of (GHEs) is developed with uniform inlet fluid temperature (UIFT) assumptions. This new method is verified against numerical and experimental results. The thermal performances of 9-borehole GHEs with different configurations are also analyzed by this new method. Based on this work, several important conclusions are obtained as follows.
(1) The new method, which relies on the assumption of uniform inlet fluid temperature rather than the uniform heat flux, can be used to study the thermal performance difference of boreholes. The effects of thermal interference have also been examined. Furthermore, the new method is flexible and has no limitations on the borehole configurations.

(2) The monthly average fluid temperature at the outlet of GHE varies each month. For $3 \times 3$ square array GHEs, due to the unbalanced annual load, the outlet temperatures will increase year over year gradually. Moreover, on the aspect of dominant mechanisms, the heat transfer can be divided into four stages in a heat transfer period. While the thermal dissipation dominates, the heat flux of the borehole with stronger thermal interference is smaller. In contrast, while the heat storage effect plays a major role, the boreholes being strongly interfered will have a greater heat flux. 
FIGURE 9: Schematic of 9-borehole GHEs in "<"-Shape (a) $\theta=\pi / 4$; (b) $\theta=\pi / 2$; (c) $\theta=3 \pi / 4$; (d) $\theta=\pi$.

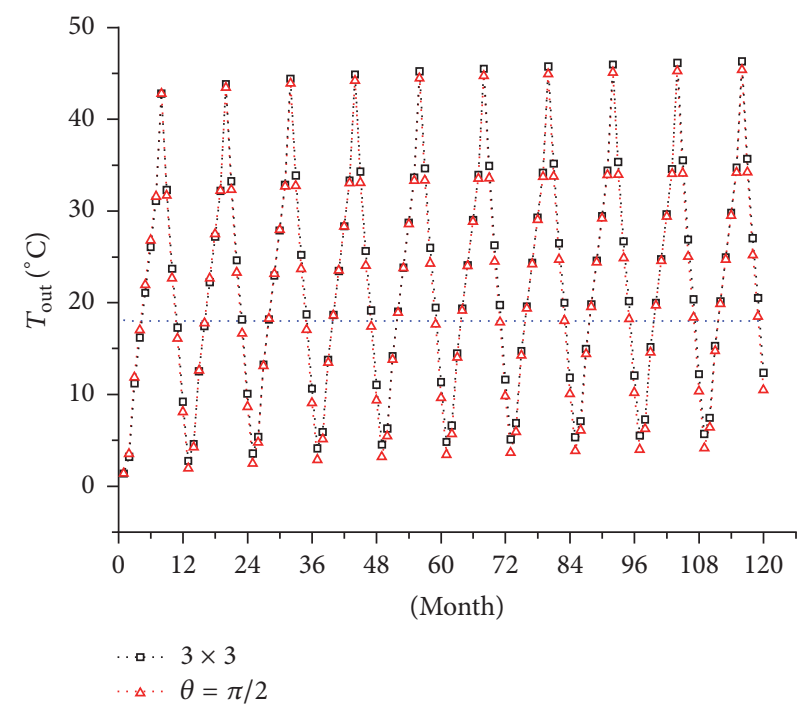

FIGURE 10: Monthly average GHEs outlet fluid temperature $(\theta=\pi / 2)$.

(3) Due to the heat accumulation, some boreholes will be malfunctioned sometimes, in particular, when individual borehole obtains heat from ground, while the GHEs are operated under the cooling mode. Obviously, this phenomenon cannot be observed under the UHF assumptions where all boreholes are assumed to yield the same heat flux. It is also shown that this phenomenon will disappear with increasing borehole spacing.

\section{Nomenclature}

A: Matrix coefficient

b: Vector coefficient

c: Specific heat

$c_{f}$ : Specific heat of fluid $e: \quad$ Thermal effectiveness

$\operatorname{Ei}(x)$ : Exponential integral function

$H$ : $\quad$ Depth of borehole, $\mathrm{m}$

$\dot{m}_{f}$ : Mass flow rate of fluid

$t: \quad$ Time

$m$ : Counter

$M_{0}$ : Total time step

$N$ : Number of boreholes

q: Thermal load/heat fluxes

$q_{s 1}$ : Is the heat flow produced by single isolated borehole, $\mathrm{W} / \mathrm{m}$

Q: $\quad$ Heat rate of GHEs

$r_{i j}$ : The space between the $i$ th borehole and the $j$ th borehole, $m$ 
TABLE 5: Average outlet fluid temperatures in 10 years.

\begin{tabular}{lcr}
\hline Case & $T_{\text {out }}$ in Aug & $T_{\text {out }}$ in Jan \\
\hline $3 \times 3$ square array & $46.3^{\circ} \mathrm{C}$ & $5.68^{\circ} \mathrm{C}$ \\
$\theta=\pi / 4$ & $45.9^{\circ} \mathrm{C}$ & $4.65^{\circ} \mathrm{C}$ \\
$\theta=\pi / 2$ & $45.4^{\circ} \mathrm{C}$ & $4.18^{\circ} \mathrm{C}$ \\
$\theta=3 \pi / 4$ & $45.3^{\circ} \mathrm{C}$ & $3.97^{\circ} \mathrm{C}$ \\
$\theta=\pi$ & $45.2^{\circ} \mathrm{C}$ & $3.92^{\circ} \mathrm{C}$ \\
\hline
\end{tabular}

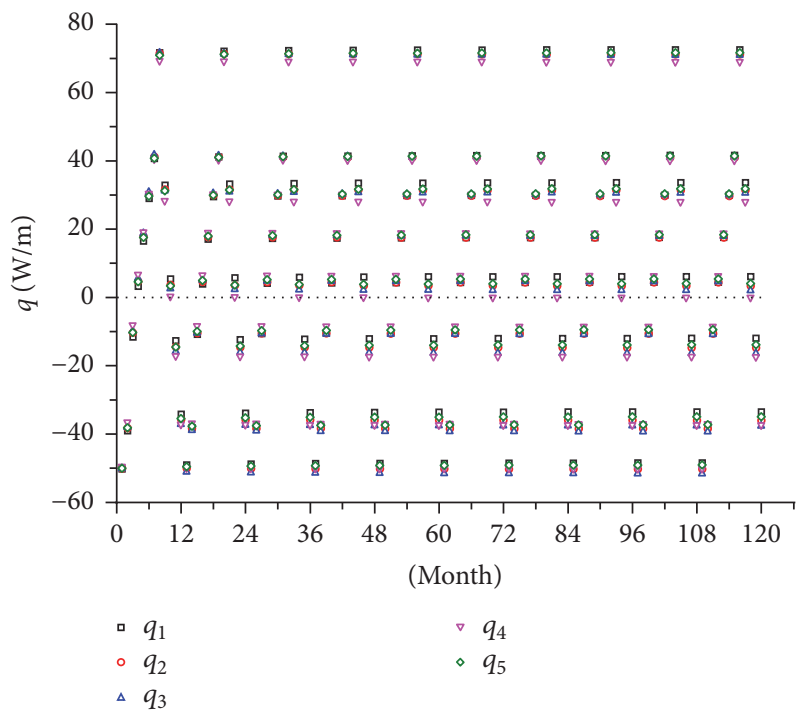

FIGURE 11: Monthly average heat fluxes for different boreholes $(\theta=$ $\pi / 4)$.

$\begin{array}{ll}r_{b}: & \text { Borehole radius, mm } \\ R_{b}: & \text { Thermal resistance in borehole } \\ R_{b t}: & \text { Coefficient, }=R_{b}+1 / \beta \\ T_{0}: & \text { Initial ground temperature, }{ }^{\circ} \mathrm{C} \\ T_{f}: & \text { The average fluid temperature } \\ T_{u}: & \text { Thermal response under unity heat flux } \\ T_{\text {in }}: & \text { The inlet fluid temperature } \\ T_{\text {out }}: & \text { Outlet fluid temperature } \\ \left(x_{w}, y_{w}\right): & \text { Location of borehole } \\ (\rho c): & \text { Volume specific heat } \\ \Delta \mathbf{q}: & \text { Heat flux vector. }\end{array}$

\section{Greek Letters}

\section{$\beta$ : Coefficient}

$\lambda$ : Thermal conductivity, $\mathrm{W} /(\mathrm{m}-\mathrm{K})$

$\rho$ : Density, $\mathrm{kg} / \mathrm{m}^{3}$

$\theta$ : Angle.

\section{Conflicts of Interest}

The authors declare that they have no conflicts of interest.

\section{Acknowledgments}

This work was supported by the National Natural Science Foundation of China no. 51674227 and the Fundamental Research Funds for the Central Universities.

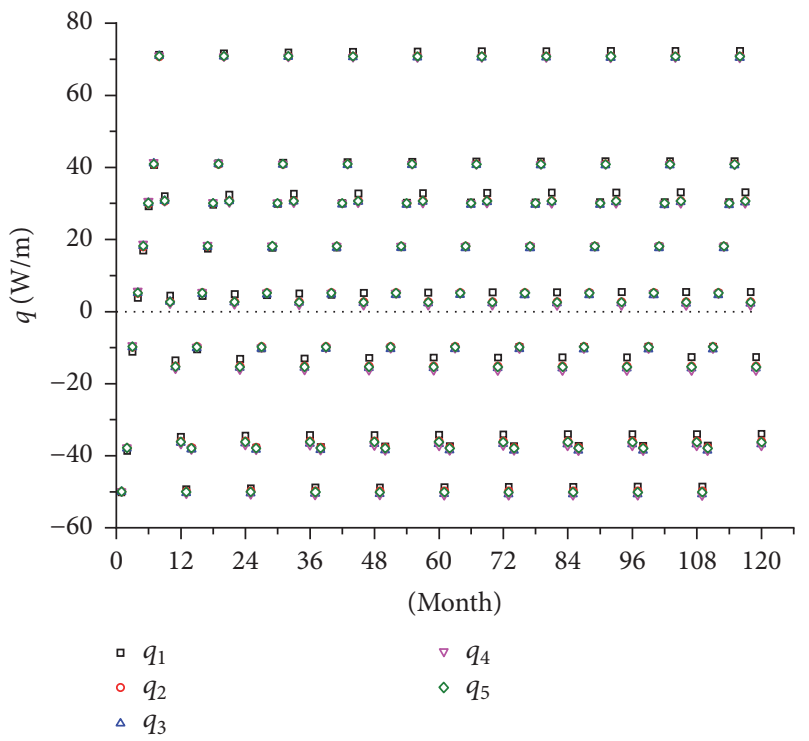

FIGURE 12: Monthly average heat fluxes for different boreholes $(\theta=$ $\pi / 2)$.

\section{References}

[1] J. Lund, B. Sanner, L. Rybach et al., "Geothermal (groundsource) heat pumps-a world overview," Geo-Heat Center Bulletin, vol. 25, no. 3, pp. 1-10, 2004.

[2] J. Claesson and P. Eskilson, "Conductive heat extraction to a deep borehole: thermal analyses and dimensioning rules," Energy, vol. 13, no. 6, pp. 509-527, 1988.

[3] S. Javed, P. Fahlén, and J. Claesson, "Vertical ground heat exchangers: a review of heat flow models," in Proceedings of the Effstock 2009 - The 11th International Conference on Energy Storage, vol. 34, pp. 1-8, Stockholm, Sweden, June 2009.

[4] W. Ruan and W. T. Horton, "Literature review on the calculation of vertical ground heat exchangers for geothermal heat pump systems," in Proceedings of the International High Performance Buildings Conference, pp. 1-5, Lafayette, Ind, USA, July 2010.

[5] S. 1. Do and J. s. Haberl, "A review of ground coupled heat pump models used in whole-building computer simulation programs," in Proceedings of the 17th symposium for improving building systems in hot and humid climates, pp. 1-9, Austin, Tex, USA, 2010.

[6] H. Yang, P. Cui, and Z. Fang, "Vertical-borehole groundcoupled heat pumps: a review of models and systems," Applied Energy, vol. 87, no. 1, pp. 16-27, 2010.

[7] Y. Man, P. Cui, and Z. H. Fang, "Heat transfer modeling of the ground heat exchangers for the ground-coupled heat pump 
systems," in Modeling and Optimization of Renewable Energy Systems, A. Şencan, Ed., pp. 117-146, InTech, 2012.

[8] W. Yang, M. Shi, G. Liu, and Z. Chen, "A two-region simulation model of vertical U-tube ground heat exchanger and its experimental verification," Applied Energy, vol. 86, no. 10, pp. 20052012, 2009.

[9] W. Kelvin, Mathematical and Physical Papers, vol. 1, Cambridge University Press, Cambridge, UK, 1882.

[10] L. Ingersoll and H. Plass, "Theory of the ground pipe heat source for the heat pump," ASHVE Transactions, vol. 54, pp. 119-122, 1948.

[11] H. Carslaw and J. Jaeger, Heat Conduction in Solids, Claremore Press, Oxford, UK, 1947.

[12] H. Y. Zeng, N. R. Diao, and Z. H. Fang, "A finite line-source model for boreholes in geothermal heat exchangers," Heat Transfer-Asian Research, vol. 31, no. 7, pp. 558-567, 2002.

[13] A. Michopoulos and N. Kyriakis, "Predicting the fluid temperature at the exit of the vertical ground heat exchangers," Applied Energy, vol. 86, no. 10, pp. 2065-2070, 2009.

[14] P. Eskilson, Thermal analysis of heat extraction boreholes [Ph.D. thesis], University of Lund, Department of Mathematics, Lund, Sweden, 1987.

[15] G. Hellström, Duct Ground Heat Storage Model: Manual for Computer Code, University of Lund, Lund, Sweden, 1989.

[16] V. Mei and C. Emerson, "New approach for analysis of groundcoil design for applied heat pump systems," ASHRAE Transactions, vol. 91, no. 2, pp. 1216-1224, 1985.

[17] N. Muraya, D. O’Neal, and W. Heffington, “Thermal interference of adjacent legs in a vertical U-tube heat exchanger for a ground-coupled heat pump," ASHRAE Transactions, vol. 102, no. 2, pp. 12-21, 1996.

[18] S. Rottmayer, W. Beckman, and J. Mitchell, "Simulation of a single vertical U-tube ground heat exchanger in an infinite medium," ASHRAE Transactions, vol. 103, no. 2, pp. 651-659, 1997.

[19] Q. Zhang, Heat transfer analysis of vertical U-tube heat exchange in a multiple borehole field for ground source heat pump systems [Ph.D. thesis], University of Kentucky, Lexington, Ky, USA, 1999.

[20] B. Xiao, W. Wang, J. Fan et al., "Optimization of the fractal-like architecture of porous fibrous materials related to permeability, diffusivity and thermal conductivity," Fractals, vol. 25, no. 3, Article ID 1750030, 9 pages, 2017.

[21] B. Q. Xiao, Y. Yang, and L. X. Chen, "Developing a novel form of thermal conductivity of nanofluids with Brownian motion effect by means of fractal geometry," Powder Technology, vol. 239, pp. 409-414, 2013.

[22] J. Cai, X. Hu, B. Xiao, Y. Zhou, and W. Wei, "Recent developments on fractal-based approaches to nanofluids and nanoparticle aggregation," International Journal of Heat and Mass Transfer, vol. 105, pp. 623-637, 2017.

[23] J. Claesson and S. Javed, "An analytical method to calculate borehole fluid temperatures for time scales from minutes to decades," ASHRAE Transactions, vol. 117, no. 2, pp. 279-288, 2011.

[24] V. Malayappan and J. D. Spitler, "Limitations of using uniform heat flux assumptions in sizing vertical borehole heat exchanger fields," in Proceedings of Clima, Prague, Czech Republic, June 2013.

[25] S. Hern, Design of an experimental facility for hybrid ground source heat pump systems [M.S. thesis], Oklahoma State University, Oklahoma, Okla, USA, 2004.
[26] J. D. Spitler, J. Cullin, M. Bernier et al., "Preliminary inter-model comparison of ground heat exchanger simulation models," in Proceedings of the 11th International Conference on Thermal Energy Storage, pp. 1-8, Stockholm, Sweden, June 2009.

[27] W. Wei and Y. Xia, "Geometrical, fractal and hydraulic properties of fractured reservoirs: A mini-review," Advances in GeoEnergy Research, vol. 1, no. 1, pp. 31-38, 2017. 

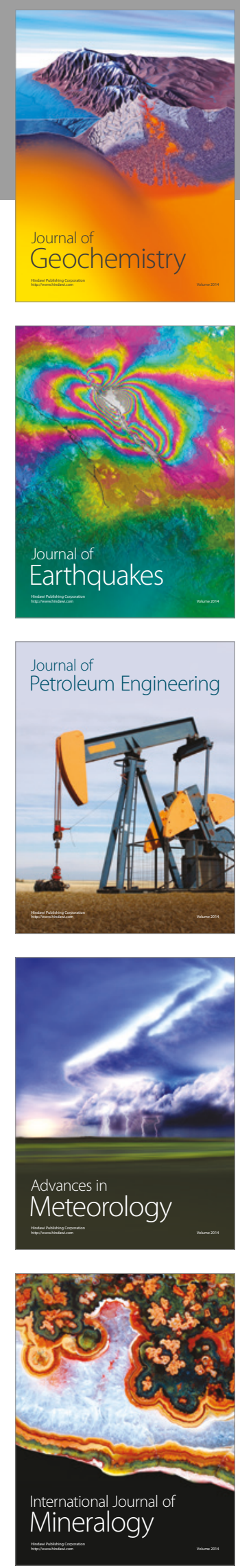
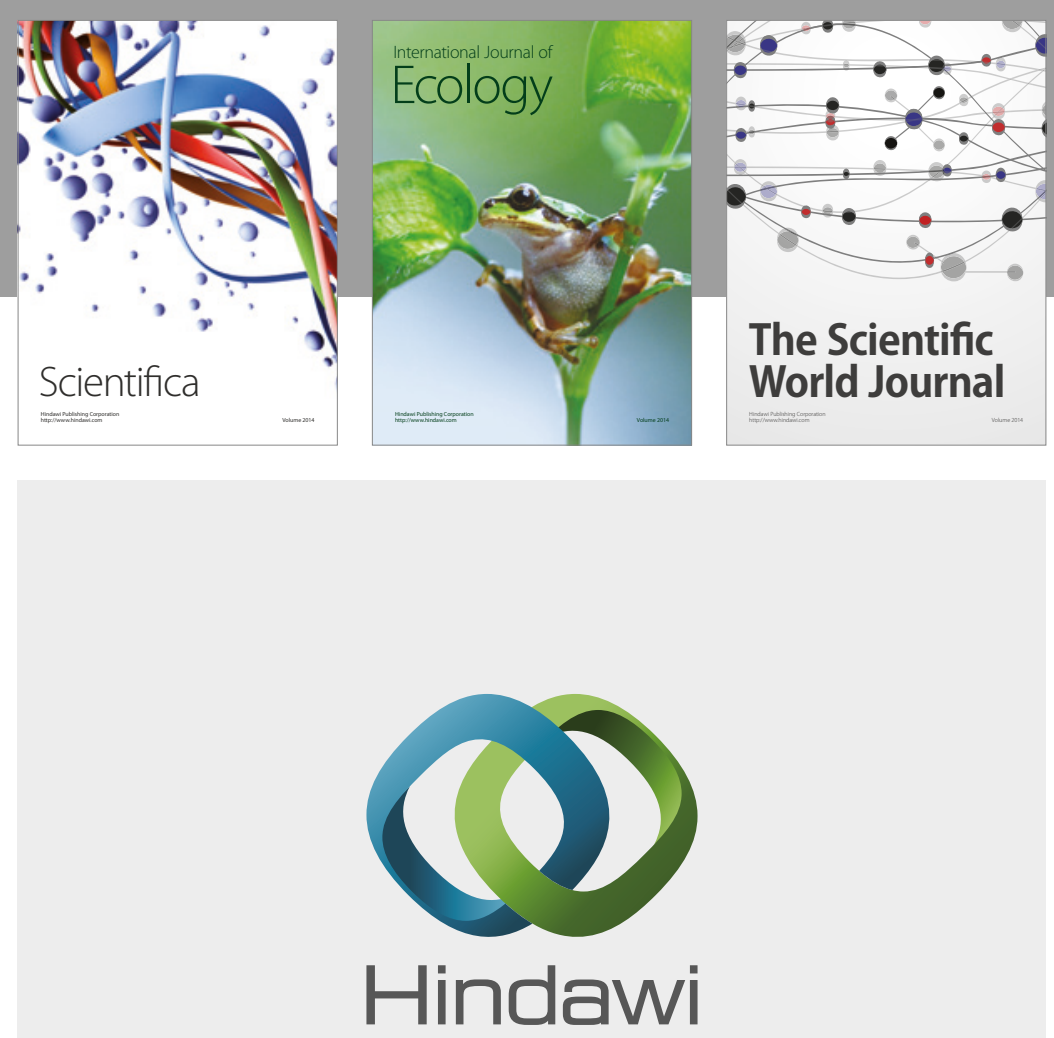

Submit your manuscripts at

https://www.hindawi.com
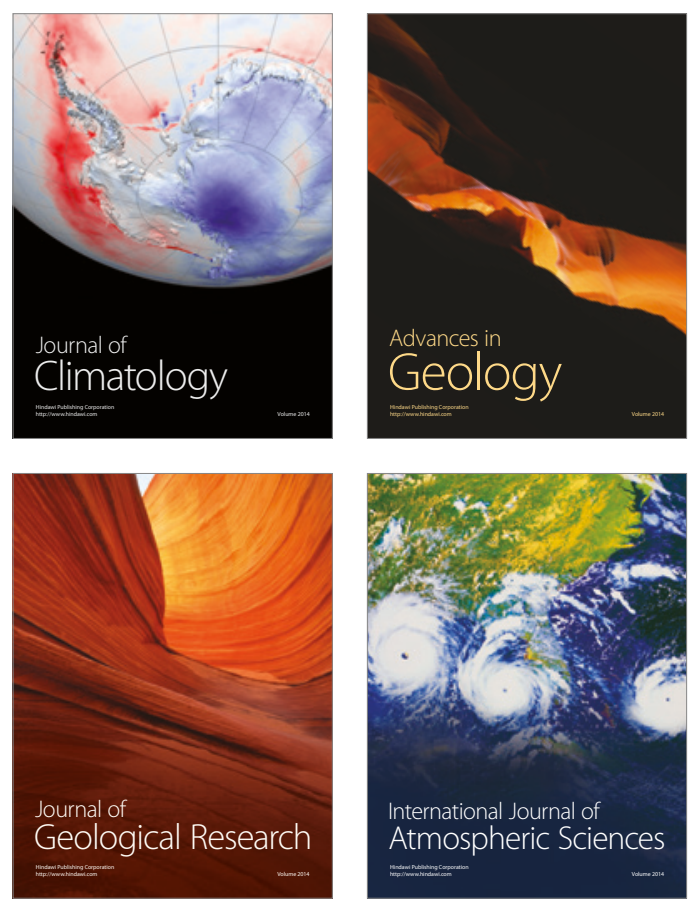

The Scientific

World Journal
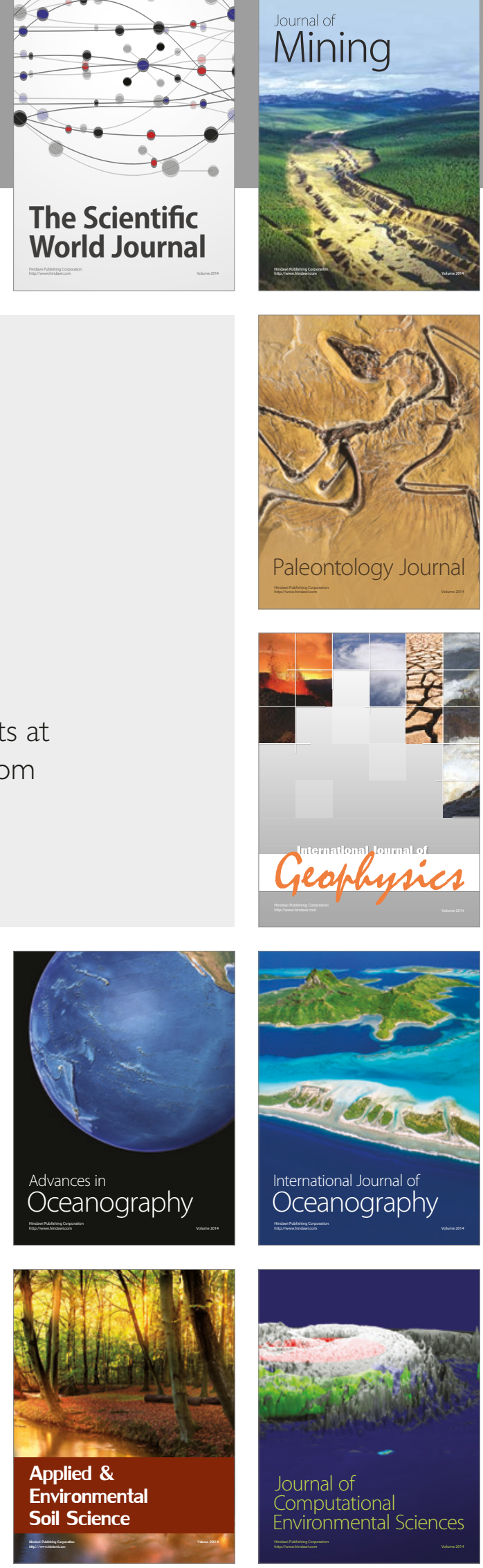